\title{
Die belang van Maleagi 1:2-5 vir die verstaan van die boek
}

A J Botha

(Universiteit van Pretoria)

\section{ABSTRACT}

The importance of Malachi 1:2-5 towards understanding of the Book Malachi

In the past years scholarly attention to the book of Malachi has been scant. The outstanding feature in most of the studies is the fact that only certain themes from the book are used. The reason for doing this is mostly to justify certain viewpoints on matters such as divorce and the giving of tithes. As James Fischer aptly remarks: "They dissect him cleanly enough but leave him a cadaver" (1973:1177). The purpose of this article is to show that a meaningful understanding of the book is only possible once it is treated as a work of unity. This inner cohesion is already found in the first pericope (Mal 1:2-5) and functions as a paradigm towards an understanding of the remainder of the book. The outline with which the paradigm works, which is copied throughout the other pericopes, is that of past $(1: 2 b-3)$, present $(1: 2 a)$ and future (1:4$5)$. Within this outline the message of the whole book can be determined.

\section{INLEIDENDE OPMERKINGS}

Die boek Maleagi kan met reg een van die afgeskeepte boeke van die $\mathrm{Ou}$ Testament genoem word. Daarvan getuig die min resente literatuur wat daaroor verskyn asook die min aandag wat dit in gespreksgeleenthede en ander teologiese debatte kry. Indien daar wel iets oor hierdie geskrif verskyn dan is dit meestal soos James Fischer dit stel: "They dissect him cleanly enough but leave him a cadaver" (1973:1177). Hierdie artikel poog om aan te toon dat daar wel ' $n$ inherente kohesie in die boek is en dat hierdie kohesie reeds in die eerste perikoop (Maleagi 1:2-5) funksioneer as ' $n$ pardigma waarmee die res van die boek gelees moet word. Hierdie paradigma werk met 'n skema van verlede $(1: 2 b-3)$, hede $(1: 2 a)$ en toekoms (1:4-5). Binne hierdie raamwerk word die res van die boodskap van die boek uitgewerk.

\section{STRUKTURELE OPBOU VAN MALEAGI 1:2-5}

Soos reeds daarop gewys, is Maleagi 1:2-5' $n$ kernperikoop in die boek Maleagi. In hierdie eerste perikoop word die sleutel waarmee die res van die perikope ontsluit word reeds gegee. Skematies kan die opbou van die perikoop as volg weergegee word (vgl Lescow 1990:197):

1 Tese (1:2a)

1.1 Openingsrede en formulering van die tese $(1: 2 a)$ 
"Ek het julle lief, sê Jahwe,"

\subsection{Teenspraak geformuleer as ' $\mathrm{n}$ vraag $(1: 2 \mathrm{a})$}

"Waarin het $U$ ons lief?"

2 Argument om hierdie tese te versterk (1:2b-3)

"Was Esau nie Jakob se broer nie? sê Jahwe en tog het ek Jakob liefgehad, maar Esau het ek gehaat. Ek het sy bergland ' $n$ verlate plek gemaak en sy erfdeel vir die woestynjakkalse gegee.

3 Begronding en slotsom van die tese (1:4-5)

As Edom sou sê: "Ons is verpletter maar ons sal terugkeer en ons sal die puinhope weer opbou" sê Jahwe Sebaoot: Hulle sal bou, ek sal afbreek. Hulle sal genoem word: "gebied van goddeloosheid" en "die volk op wie die toorn van Jahwe vir altyd rus". En julle eie oë sal dit sien en julle sal sê: "Jahwe is groot oor die hele gebied van Israel".

Maleagi 1:2-5 se mees opvallende verskil met die ander perikope lê in die feit dat daar nie in hierdie perikoop sprake is van ' $n$ aanklag van Jahwe teen sy volk nie. Trouens, dit open met 'n onbevange liefdesverklaring van Jahwe: Ek het julle lief. Hierdie verskil is egter nie net toevallig nie. Deur hierdie liefdesverklaring heel aan die begin van die boek te plaas, begin Maleagi met ' $n$ baie bekende tema van die Deuteronomis: God se verbondsliefde vir sy volk. Soos die Deuteronomis poog hy om die kultusgemeenskap te help om nie net in die krisis van die hede vas te kyk nie, maar om getrou te wees aan die verbond. Die verbond van God met Israel funksioneer juis as die waarborg van die verlede vir die hede en die toekoms.

Die hoop vir die hede en die toekoms word gebou op die liefde (אהב) van Jahwe. Jahwe se liefde word egter nie hier as imperatief gebruik nie, maar as ' $n$ deklarasie van voorneme (indikatief) van Jahwe. Wat hierdie indikatief behels, word in die res van die perikoop uitgewerk aan die hand van die verlede (Jakob wat gekies is - 1:2b-3), die hede (Jahwe se onwankelbare liefde - 1:2a) en die toekoms (dit wat Jahwe gaan doen - 1:4-5). Deur die verlede stilisties in die middel te plaas laat val Maleagi die klem op die belang van die verlede. Die hoop vir die hede en die toekoms word gebou op Jahwe se troue verbondsliefde in die verlede.

\subsection{Tese (1:2a)}

Jahwe se liefde vir die volk binne hulle huidige omstandighede word in die tese van 1:2a op geen onseker wyse gestel nie. Beide op sintaktiese en grammatiese vlak word hierdie liefde van Jahwe, wat steeds in die hede geldig is, beklemtoon.

Beide Snyman (1985:64 en 1986:436-438) en Reventlow (1993:134) het die chiasme in 1:2a raakgesien en die belang daarvan vir 
die verstaan van die boodskap aangedui. Skematies kan die chiasme soos volg weergegee word:

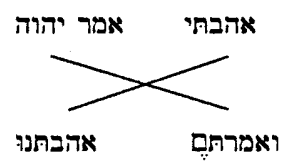

In hierdie parallelle chiasme (Snyman 1985:65) word die liefde van Jahwe teenoor die teenvraag van Israel gestel. Die doel van ' $n$ parallelle chiasme is gewoonlik om ' $n$ bepaalde saak te beklemtoon, in hierdie geval, die liefde van Jahwe. Die klem word verder op Jahwe se liefde geplaas deur die twee aktante van die chiasme antiteties teenoor mekaar te stel: Jahwe, die troue Verbondsgod, teenoor die volk se "julle" (Snyman 1986:436). Die woord אהב word egter nie willekeurig gebruik nie. Maleagi gebruik אהב hier intensioneel, soos Deuteronomium, as 'n verbondswoord. W L Moran (1963:77-87) maak veel daarvan om aan te toon dat God se liefde as ' $n$ verbondsliefde funksioneer. Op grond daarvan kan Hy sekere eise aan sy verbondsvolk stel. En verder "The word love (אהב) is a covenant word. It is also an election word. God chose Israel because He loved her (Deut 7:8)" (R L Smith 1984:305). Dit is duidelik dat Maleagi hierdie lyn volg in sy gebruik van die term אהב. Hiermee sê Jahwe dus duidelik sy liefde vir die volk in die hede is nie maar net ' $n$ mooiweersliefde nie, maar ' $n$ verkiesende verbondsliefde met sy wortels stewig in die toetsbare verlede. Soos Verhoef (1972:84) dit stel, die liefde van God is sinoniem met sy verkiesing. Die fondament waarop Jahwe se verbond met die volk rus, is sy liefde (vgl Deut 7:7-8, 12-14).

Hierdie beklemtoning word verder versterk deur die werkwoordsvorm van אהב. Soos dit hier in die teks staan, is אהבתי die eerste persoon enkelvoud Qal perfektum van אהב. Hiervolgens sou dit lyk asof die argument dat Jahwe se liefde hier op die hede gerig is, verval. Die werkwoordvorm dui egter eerder ' $n$ beklemtoning van Jahwe se ewigdurende liefde aan. J M P Smith (1912:20) sê: "The tense of the verb indicates a love that has not only operated in the past, but is also in effect at the present". (Kursivering myne). Die belangrikste argument om אהבתי wel in die teenwoordige tyd weer te gee en te verklaar, kom in Gesenius' Hebrew Grammar in sy uitleg oor die gebruik van die perfektum (Ges-K 1910:309-311) voor. In die inleiding oor die gebruik van die perfektum sê hy:

"The perfect serves to express actions, events, or states which the speaker wishes to represent from the point of view of completion, whether they belong to a determinate past time, or extend into the 
present, or, while still future, are pictured in their completed state" (Ges-K 1910:§106a).

Die perfektum dui dikwels op ' $n$ handeling of toestand wat volgens die verband langer of korter kan duur. Wanneer die gevolg van so ' $n$ handeling tot in die hede bly voortduur, kan die betrokke werkwoord in die praesens weergegee word (Ges-K 1910:\$106g). In hierdie geval (1:2a) word אהבתי nie gebruik om slegs ' $n$ werking in die verlede aan te dui nie, maar eerder om aan te toon dat die gevolge van hierdie handeling nie in die verlede afgehandel is nie, maar steeds bly voortduur tot in die hede.

Deur hierdie verbondsterm (אהב) heel aan die begin van die perikoop en die boek te plaas, maak Maleagi ' $n$ stelling oor die verhouding tussen Jahwe en die volk. Die stelling wat hy hier in die tese maak is: "Ek het julle lief!" Dit geld vir die hede, al sou die omstandighede nie noodwendig lyk soos hulle dit wil hê nie. Deur die geskiedenis was liefde, verkiesing en verlossing nog altyd skakels in die ketting van God se bemoeienis met sy volk (vgl Deut 4:37-40). Hiermee bevestig die skrywer van Maleagi God se onveranderlike blywende liefde wat deur die verlede tot in die hede strek.

\subsection{Argument om hierdie tese te versterk (1:2b-3)}

Die indikatief van $1: 2 \mathrm{a}$ word nou verder begrond deur terug te verwys na die verlede (1:2b-3). Op hierdie wyse toon Jahwe vir die volk dat sy liefde nie net vir die huidige geld nie, maar dat dit in die toetsbare geskiedenis van die verlede geanker is. Jahwe se antwoord oor sy liefde vir Jakob en sy haat vir Esau volg juis op die במה vraag van die volk: Dit toon aan dat Jahwe se liefde nie sporadies funksioneer nie, maar deurlopend - uit die verlede in die hede en tot in die toekoms.

Die geskiedenis waarop Maleagi nou terugval is dié van die aartsvaders. Soos Verhoef (1972:84-85) dit stel: "Zijn liefde begint ver terug in de geschiedenis met de roeping van Abraham (Jes 41:8; 2 Kron 20:7), en de betoning van zijn liefde aan de aartsvaders" (Deut 4:37; 10:15). McKenzie en Wallace (1983:555-557) het myns insiens die essensie van $1: 2 b-3$ raakgevat deur aan te toon dat dit hier gaan oor ' $n$ teruggrype na die aartsvadertradisies, met name die tradisie rondom Jakob. Deur die aartsvader Jakob (kleinseun van Abraham en seun van Isak) te gebruik, word Israel teruggevoer na die wortels van hulle bestaan (vergelyk die opmerking van Snyman (1988:71) oor die aartsvaders).

In die eerste plek word die beloftes aan die aartsvaders hiermee voor oë geroep: die belofte van die land om in te woon en daarmee saam Jahwe se belofte om binne die land versorgend teenoor hulle op te tree. Soos Rudolph (1976:255-256) dit stel: “...so ist damit klar, daß sich im Verhalten Jahwes seit der Väterzeit nichts geändert hatte, daß seine Liebe also nach wie vor den Nachkommen Jakobs, den Juden, galt...”. So 
word gewys dat hulle geskiedenis in die verlede ' $\mathrm{n}$ lang geskiedenis van God se liefde en bemoeienis met die volk is (verlede en hede). In die tweede plek wys dit ook vir die volk presies waar hulle vandaan kom. Jakob is hulle voorvader (Gen 25-35). Binne die konteks van die aartsvadertradisies sou die naam van Jakob beslis bepaalde herinneringe by die volk oproep. Van die begin van sy lewe af was Jakob ' $n$ man wie se lewe gekenmerk is deur bedrog en selfs leuens en oneerlikheid (vgl Gen 25, 27 en 30). Dwarsdeur hierdie geskiedenis van Jakob bly Jahwe egter getrou aan sy woord dat Jakob die geseënde een sal wees deur wie Hy ook sy volk sal seën (vgl Gen 25:23, 28:13-15, 35:10-15). Deur Jakob as subjek van sy liefde aan die volk voor te hou, fokus Jahwe die volk se aandag op sy onveranderlike trou dwarsdeur die geskiedenis (verlede) in teenstelling met hulle ontrou en leefwyse as kinders van Jakob (verlede en hede).

Oor die vraagstuk van wat presies bedoel word met Jahwe se liefde vir Jakob en sy haat vir Esau (1:2b-3), is deur die eeue reeds baie geskryf. Die standpunte hieroor is egter baie uiteenlopend. Opsommend kan die volgende genoem word:

* Jahwe se haat vir Esau moet gesien word teen die agtergrond van die verslegtende verhouding tussen die Jode en die Edomiete (GlazierMcDonald 1987:34-35).

* ' $n$ Ander oplossing wat aangebied word, is dat liefde en haat gesien moet word as "meer geliefd" en "minder geliefd" (Kaiser 1984:27).

* Elliger (1967:190) sien die teenstelling as dat Jakob voorgetrek is en Esau (zurückgesetzt) gelos is om sy gang te gaan (vgl ook Deissler 1988:319). In hierdie standpunt is liefde en haat nie twee absolute teenoorgesteldes nie. Dit kom naastenby by dieselfde gedagte uit as die bogenoemde standpunt van Kaiser, naamlik, dat die een meer liefde kry as die ander. Die gedagte wat dus hier beklemtoon word, is dat daar met beide partye ' $n$ liefdesverhouding is.

* Die mees algemene verklaring is dat die teenstelling tussen liefde en haat gesien moet word binne die raamwerk van die verkiesing. Jahwe het in sy vrymagtigheid (...aus freien Stücken und aus freier Wahl...) vir Jakob as objek van sy liefde gekies (Rudolph 1976:255).

$\mathrm{Na}$ aanleiding van dit wat reeds oor die aartsvadertradisie gesê is, lyk dit tog asof hier " $n$ ander moontlikheid is. Sintakties word hierdie liefde en haat in ' $\mathrm{n}$ antitetiese chiasme teenoor mekaar gestel (vgl Snyman 1984:361; 1985:65; 1986:437; Reventlow 1993:134). Skematies kan die chiasme as volg weergegee word: 


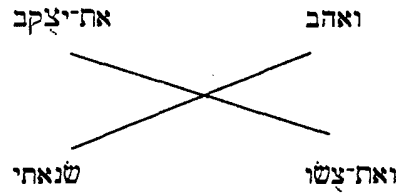

In hierdie chiasme kry ons die twee eiename, Jakob en Esau, wat as twee pole teenoor mekaar staan in die een been. Beide word voorafgegaan deur die partikel את (Ges-K 1910:\$117a) wat die verband tussen die twee pole nog verder versterk (Snyman 1984:361). In die ander been word liefde en haat as die twee pole teenoor mekaar gestel. Die feit dat beide die werkwoordsvorme in die eerste persoon enkelvoud staan en dat "de tijdssfeer van... (צנא) overeen (komt) met die van de voorafgaande verba" (Verhoef 1972:87), versterk die verband tussen die twee pole nog verder. Reventlow (1993:134) sê: "Das Verb am Anfang muß man präsentisch wiedergeben; es drückt ebenso wie die entsprechende antitetische Aussage V.3a eine dauernde Haltung Jahwes Israel gegenüber aus". Jahwe se haat vir Esau en sy liefde vir Jakob word dus in hierdie chiasme antiteties teenoor mekaar gestel. Die toespitsing van hierdie chiasme is egter nie Jahwe se haat vir Esau nie, maar sy voortgaande versorgende handeling met sy verbondsvolk. "Nicht Erwählung Israels und Verwerfung Edoms sollen einander gegenübergestellt werden, sondern, wie die sofort anschließende Frage der Hörer zeigt, eine auf konkretes Handeln gerichtete Grundhandlung Jahwe" (Reventlow 1993:135). Esau en Jakob, liefde en haat word as antiteses teenoor mekaar gestel om die klem op Jahwe se liefde te laat val. Soos Snyman (1986:438) sê: "To put it bluntly: not too much should be made of Yahweh's hate for Esau/Edom in this pericope, being part of a chiasmus and considering the context of the statement, it is rather the love of Yahweh which is emphasised".

Indien die twee chiasmes nou met mekaar vergelyk word, is dit opvallend dat die tertium comparationes van beide dele die liefde van Jahwe is. Samevattend kan ons sê in die parallelle chiasme van 1:2a word die liefde van Jahwe vir die volk in die hede beklemtoon. In die antitetiese chiasme van 1:2b-3 val die klem op Jahwe se liefde vir die volk soos dit in die verlede reeds bevestig is (vgl ook G Wallis 1974:112-113). So word die "waarin (במה) vraag" van die volk nie net vanuit die hede beantwoord nie, maar dit is gewortel in die geskiedenis (die verlede) van die volk.

\subsection{Begronding en slotsom van die tese (1:4-5)}

In die slot van die perikoop word die hele argument oor die liefde van Jahwe saamgevat en word die paradigma vir die res van die boek voltooi. In die slotsom toon Maleagi aan dat nie net die hede en die verlede 
bevestiging is van Jahwe se liefde nie, maar dat ook die toekoms ' $n$ getuie hiervan sal wees (Snyman 1988:71).

Dit word gedoen deur in hierdie slotgedeelte te wys op die lot wat op Edom wag. Edom se reaksie hierop is egter nie so gunstig nie en dit wat hulle in 1:4 sê: (כי־תאמר אדום), word gekontrasteer met כה אמר יהוה. Die wyse waarop Edom se woorde met dié van Jahwe gekontrasteer word, beklemtoon die futiliteit van enige poging van hulle kant af om dit wat Jahwe reeds besluit het ongedaan te probeer maak. Al sou hulle ook probeer opbou, Jahwe het reeds sy besluit geneem en daarom sal dit nie gebeur nie.

Hierdie ingrype van Jahwe in die toekoms word stilisties verder versterk deur "bou" en "afbreek" in die vorm van "n chiasme teenoor mekaar te stel (Snyman 1986:438):

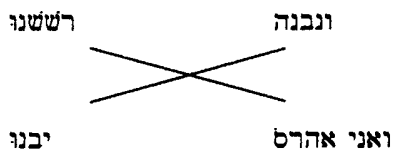

Uit hierdie chiasme is dit duidelik dat Edom se lot in die toekoms deur Jahwe bepaal word. Soos Snyman (1985:78) dit stel: "Wat Edom na sy verwoesting wil opbou, sal Jahwe afbreek. In Jahwe se reaksie op die menslike hubris van Edom word die בנה (bou) as laaste werkwoord in Edom se antwoord op die verwoesting opgeneem in Jahwe se antwoord aan Edom. Geen poging van Edom om Jahwe se oordeel ongedaan te maak, sal slaag nie". Dit word duidelik uitgespel dat Jahwe die een is wat vir Edom se katastrofiese ondergang verantwoordelik is.

Teenoor hierdie lot wat vir Edom in die toekoms wag, staan die toekoms vir Israel in die teken van verlossing. Edom, die "gebied van goddeloosheid" wat verwoes word en op wie die toorn van Jahwe vir altyd rus (1:4); en Israel, die gebied met 'n toekoms op grond van die grootheid en die ingrype van Jahwe. Op grond van hierdie gebeure in die toekoms sal die volk getuig dat Jahwe inderdaad groot is oor die hele gebied van Israel (1:5).

\section{KONKLUSIE}

Uit die voorafgaande opbou lyk dit moontlik om te konkludeer dat Maleagi 1:2-5 die tese van die hele boek stel: God se onwankelbare verbondsliefde vir sy volk. Hierdie blywende verbondsliefde as troos vir die volk word gemotiveer vanuit die hede (Ek het julle lief), die verlede (Jakob het Ek liefgehad en Esau het Ek gehaat) en die toekoms (die lot van Edom wat kontrasteer met die toekoms van Israel). Dit is opvallend dat die volgorde (hede, verlede en toekoms) omgeruil is. Deur die verlede en daarmee die verkiesing van Jakob in die sentrum te plaas, word 
die fokus op Jahwe se heilsdade van die verlede geplaas. Hiermee word die verlede dan ook die maatstaf waaraan Jahwe se liefde in die hede gemeet kan word. Dit word ook die fondament waarop die hoop vir die toekoms gebou kan word. Deur die klem op hierdie wyse op die verlede te laat val, funksioneer Maleagi 1:2-5 binne die groter raamwerk van die boek as verteenwoordiger van die verlede. Die paradigma van verlede, hede en toekoms, wat in Maleagi 1:2-5 gestel word, dien egter ook as die paradigma waarmee die res van die boek ontsluit word.

In die volgende perikope (1:6-2:9, $2: 10-16,2: 17-3: 5$ en $3: 6-12)$ word die troue liefde van Jahwe gemeet aan die volk se optrede in die HEDE. Die laaste perikoop (3:13-21), asook die slotwoord van 3:22-24 plaas die troosvolle werking van Jahwe binne die raamwerk van die eskatologie, wanneer alles wat Jahwe in die VERLEDE (1:2-5) en die HEDE (1:6-2:9, 2:10-16, 2:17-3:5 en 3:6-12) gesê het realiteit word in die TOEKOMS (3:13-21 en 3:22-24). Saamgevat kan ons sê die sondige hede omring word deur God se verbondstrou van die verlede (Mal 1:2-5) en die belofte van ' $n$ toekoms vir sy volk in 3:13-21 en 3:22-24 (vgl ook Van Selms (1975:35) en Snyman (1990:205).

\section{Literatuurverwysings}

Achtemeier, E 1986. Nahum-Malachi. Interpretation. A Bible Commentary for Teaching and Preaching. Atlanta: John Knox Press.

Ackroyd, P R 1968. Exile and Restoration: A study of Hebrew Thought of the Sixth Century B.C. Philadelphia: Westminister Press.

Baldwin, J G 1972. Haggai, Zechariah, Malachi. An Introduction and Commentary.

Tyndale Old Testament Commentaries. London: The Tyndale Press.

Bauer, L 1992. Zeit des Zweiten Tempels-Zeit der Gerechtichkeit. Zur sozioökonomischen Konzeption im Haggai-Sacharja-Maleachi-Korpus. Beiträge zur Erforschung des Alten Testaments und des Antieken Judentums, Band 31. Frankfurt am Maim: Peter Lang.

Berquist, J L 1989. The Social Setting of Malachi. BTB 19, 121-125.

Blake, R D 1988. The rhetoric of Malachi. Michigan: U M I.

Botterweck, G J en Ringgren, H, red. 1974-1975. Theological Dictionary of the Old

Testament. Volume 1 en 2. Vertaal deur Willis J Grand Rapids: William B Eerdmans Publishing Company. (Afgekort: TDOT.)

Braun, R 1977. Malachi - A Catechism for Times of Disappointment. Currents in Theology and Mission 4, 297-303.

Bright, J 1972. A History of Israel. Second Edition. London: SCM Press Ltd.

Brown, F, Driver, F S, Briggs, C A, red. 1907. A Hebrew English Lexicon of the Old Testament. Herdruk 1974. Oxford: Clarendon Press. (Afgekort: BDB.)

Brown, W P 1996. Obadiah through Malachi. Westminister Bible Companion. Kentucky: Westminister John Knox Press. 
Burden, J J en Prinsloo, W S, reds. 1987. Tweegesprek met God. Predikers, digters en wysgere. Die literatuur van die Ou Testament. Deel 3. Kaapstad: TafelbergUitgewers.

Clements, R E 1975. Prophecy and Tradition. Growing points in Theology. Oxford: Basil Blackwell.

-, 1987. Old Testament Theology. A fresh approach. London: Marshall, Morgan and Scott.

Clendenen, R E 1987. The structure of Malachi: A textlinguistic study. CTR 2.1, 317.

Collins J J 1984. The Message of Malachi. The Bible Today 22, 209-215.

Deddens, K 1970. Maleachi's Dialogen. Goes: Oosterbaan \& Le Cointre.

Deissler, A 1988. Zwölf Propheten III. Die Neue Echter Bibel. Kommentar zum Alten Testament mit der Einheitsübersetzung. Würzburg: Echter Verlag.

Deist, F E 1976. Die dag sal brand. Kaapstad: NGK Uitgewers.

Driver, S R 1906. The Minor Prophets. New York: Oxford University Press.

Dumbrell W J 1976. Malachi and the Ezra-Nehemiah Reforms. The Reformed Theological Review 35, 42-52.

Eichrodt, W 1975. Theology of the Old Testament. Volume 1. London: SCM

-, 1975. Theology of the Old Testament. Volume 2. London: SCM

Eissfeldt, O 1965. The Old Testament: An Introduction. New York: Harper and Row.

Elliger, K 1963. Maleachi und die Kirchliche Tradition, in Tradition und Situation. Studien zur alttestamentlichen Prophetie. Würthwein E en Kaiser O (reds), Festschrift Artur Weiser zum 70. Geburtstag. Göttingen: Vandenhoeck \& Ruprecht.

-, 1967. Das Buch der zwölf kleinen Propheten II. Die Propheten Nahum, Habakuk, Zephanja, Haggai, Sacharja, Maleachi. Das Alte Testament Deutsch. Teilband 25. Göttingen: Vandenhoeck \& Ruprecht.

Eybers, I H 1970. Malachi - The Messenger of the Lord. Theologia Evangelica 1, 12-20.

Fischer, J A 1972. Notes on the literary from and message of Malachi. $C B Q 34,315-$ 320.

Fischer, J A 1973. Understanding Malachi. The Bible Today 66, 1173-1177.

Fohrer, G 1972. Theologische Grundstrukturen des Alten Testaments. Berlin: Walter de Gruyter.

Glazier-McDonald, B 1987. Malachi. The Divine Messenger. Atlanta, Georgia: Scholars Press.

Gordon, R P 1994. Studies in the Targum to the twelve prophets. From Nahum to Malachi. Supplements to Vetus Testamentum. Volume LI. Leiden: E J Brill.

Gowan, D E 1986. Eschatology in the Old Testament. Philadelphia: Fortress Press.

Graffy, A 1984. A prophet confronts his people. The disputation speech in the prophets. Rome: Biblical Institute Press.

Gray, S W 1987. Useless Fires: Worship in the Time of Malachi. SWJT 30, 35-41. 
Hanson, P D 1987. The People Called. The Growth of Community in the Bible. San Fransisco: Harper \& Row, Publishers.

Haran, M 1978. Temples and temple-service in Ancient Israel. An inquiry into the character of cult phenomena and the historical setting of the Priestly school. Oxford: Clarendon Press.

Harrison, R K 1975. Introduction to the Old Testament with a comprehensive review of Old Testament studies and a special supplement on the Apocrypha. Grand Rapids, Michigan: William B Eerdmans Publishing Company.

Heflin, J N 1987. The prophet Malachi, His World and His Book. SWJT 30, 5-11.

Holtzman, O 1931. Der Prophet Maleachi und der Ursprung des Pharisäerbundes. Archiv für Religionswissenschaft 29, 1-21.

Horst, F 1964. Die Zwölf kleinen Propheten: Nahum bis Maleachi. Handbuch zum Alten Testament. Tübingen: J C B Mohr.

Kaiser, W C 1984. Malachi. God's unchanging love. Grand Rapids, Michigan: Baker Book House.

Kaiser, W C (Jr). 1979. Toward an Old Testament Theology. Grand Rapids, Michigan: Zondervan Publishing House.

Kautzsch, E, ed. 1910. Gesenius' Hebrew Grammar. Second English Edition revised by A E Cowley. Oxford: Clarendon Press. (Afgekort: Ges-K).

Klein, G L 1987. An Introduction to Malachi. CTR 2.1, 19-37.

Kodell, J 1982. Lamentations, Haggai, Zechariah, Malachi, Obadiah, Joel, Second Zecharaih, Baruch. Old Testament Message. A Biblical-Theological Commentary. Volume 14. Delaware: Michael Glazier, Inc.

Koehler, L, Baumgartner, W, red. 1958. Lexicon in Veteris Testamenti Libros. Leiden: E J Brill. (Afgekort: KB).

Lescow, T 1990. Dialogische Strukturen in den Streitreden des Buches Maleachi. ZAW 102, 194-212.

Levine, B A 1974. In the presence of the Lord. A study of cult and some cultic terms in Ancient Israel. Leiden: E J Brill.

Maarsingh, B 1980. Leviticus. Tweede herziene druk. De prediking van het Oude Testament. Nijkerk: Uitgeverij G F Callenbach B.V.

Maier, G 1985. Der Prophet Haggai und der Prophet Maleachi. Wuppertaler Studienbibel. Wuppertal: R Brockhaus.

Mason, R 1977. The books of Haggai, Zechariah and Malachi. The Cambridge Bible Commentary. Cambridge: Cambridge University Press.

McCarthy, D J 1965. Notes on the Love of God in Deuteronomy and the Father-Son Relationship between Yahweh and Israel. $C B Q 27,144-147$.

McKenzie, S L \& Wallace H N 1983. Covenant themes in Malachi. $C B Q 45$ (4), 549-563.

Meyers, E M 1986. Priestly Language in the Book of Malachi. Hebrew Annual Review 10, 225-237.

Moran, W L 1963. The Ancient Near Eastern Background of the Love of God in Deuteronomy. $C B Q 25,77-87$.

Mowinckel, S 1953. Religion und Kultus. Göttingen: Vandenhoeck \& Ruprecht. 
Noth, M 1981. The Deuteronomistic history. Editors: D J A Clines, P R Davies, D M Gunn. JSOTS 15. Sheffield: JSOT Press.

-, 1987. The Chronicler's history. Editors: D J A Clines, P R Davies. Translated by H G M

Williamson. JSOTS 50. Sheffield: JSOT Press.

O'Brien, J M 1990. Priest and Levite in Malachi. Atlanta, Georgia: Scholars Press.

-, 1996. Judah as Wife and Husband: Deconstructing Gender in Malachi. JBL 115/2, 241-250.

Ogden, G S and Deutsch, R R 1987. A Promise of Hope - A Call to Obedience. A Commentary on the Books of Joel and Malachi. International Theological Commentary. Grand Rapids, Michigan: W M B Eerdmans.

Pfeiffer, E 1959. Die Disputationsworte im Buche Maleachi. Ein Beitrag zur formgeschichtlichen Struktur. Evangelische Theologie 19, 546-568.

Prinsloo, W S en Vosloo W, reds. 1987. Ou Testament teologie: Gister vandag en môre. Universiteit van Pretoria teologiese studies no 4. Pretoria: NGKB.

Redditt, P L 1994. The Book of Malachi in its Social Setting. $C B Q 56,240-255$.

Reventlow, H G 1993. Die propheten Haggai, Sacharja und Maleachi. Das Alte Testament Deutsch. Teilband 25/2. Göttingen: Vandenhoeck \& Ruprecht.

Rowley, H H 1967. Worship in ancient Israel. It's forms and meaning. London: SPCK.

Rudolph, W 1976. Haggai - Sacharja 1-8 - Sacharja 9-14 - Maleachi. Kommentar zum Alten Testament. Band $\mathrm{XIII}_{4}$. Gütersloh: Gütersloher Verlagshaus Gerd Mohn.

Sellin, D E 1930. Das Zwölfprophetenbuch übersetz und erklärt. Kommentar zum Alten Testament, Band XII, zweite Hälfte. Leipzig: A Deichertsche Verlagsbuchandlung.

Smith J M P 1912. Malachi. The International Critical Commentary. Edinburgh: T\&T Clark.

Smith R L 1984. Micah-Malachi. Word Biblical Commentary. Vol.32. Waco Texas: Word Books.

-, 1987. The Shape of Theology in the Book of Malachi. SWJT 30, 22-27.

Snyman, F 1995. Gesprek met God. Maleagi die woord vir die mense. Halfway House: Orion Uitgewers.

Snyman, S D 1984. Haat Jahwe vir Esau? NGTT 25 (4), 358-362.

,- 1985 . Antiteses in die boek Maleagi. Ongepubliseerde DD verhandeling. Universiteit van Pretoria.

-, 1986. Antithesis in Malachi 1,2-5. ZAW 98 (3), 436-438.

-, 1988. Eschatology in the book of Malachi. OTE 1/2, 63-77.

-, 1990. Antithesis in the book Malachi. Journal of Northwest Semitic Languages XVI, 173-178.

-, 1990. Op weg na 'n teologie van die boek Maleagi. Tydskrif vir Geesteswetenskappe 30 (3), 204-212.

Soggin, J A 1980. Introduction to the Old Testament. Vertaling van oorspronklike: Introduzione all' Antico Testamento, deur John Bowden. London: SCM Press. 
Tillman, W M 1987. Key Ethical Issues in Malachi. SWJT 30, 42-47.

Van der Woude, A S 1982. Haggai/Maleachi. De Prediking van het Oude Testament. Nijkerk: G F Callenbach bv.

Van Gemeren, W A 1990. Interpreting the Prophetic Word. Grand Rapids, Michigan: Zondervan Publishing House.

-, 1997. New International Dictionary of Old Testament Theology \& Exegesis.Volume 1 to Volume 4. Grand Rapids, Michigan:Zondervan Publishing House.

Van Selms, A 1971. The inner cohesion of the book Malachi in van Wyk, W C (red) Studies in Old Testament Prophecy. OTWSA, 27-40.

Verhoef, P A 1972. Maleachi. Commentaar op het Oude Testament. Kampen: J H Kok.

Von Rad, G 1975. Old Testament Theology. Volume 1. London: SCM.

-, 1975. Old Testament Theology. Volume 2. London: SCM.

Vosloo, W 1975. Op soek na die oorsprong van die begrip "Die dag van die Here". Theologia Evangelica 8(3), 183-189.

Vriezen, Th. C 1977. Hoofdlijnen der theologie van het Oude Testament. Wageningen: $\mathrm{H}$ Veenman en Zonen.

Weiser, A 1961. Introduction to the Old Testament. Vertaling van oorspronklike Einleitung in das Alte Testament, deur D M Barton. London: Darton, Longman \& Todd Ltd.

Zimmerli, W 1978. Old Testament Theology In Outline. Vertaling van oorspronklike Grundriss der alttestamentlichen Theologie deur D E Green. Edinburgh: T\&T Clark Ltd. 